\title{
"All in One or (W)hole in One Repair" for Adult Total Brachial Plexus Palsy
}

\author{
V. Purushothaman ${ }^{1} \quad$ K. Vinoth Kumar ${ }^{1}$ Sabari Girish Ambat ${ }^{1} \quad$ R. Venkataswami ${ }^{1}$ \\ ${ }^{1}$ Department of Plastic and Reconstructive Surgery, Apollo First \\ Address for correspondence V. Purushothaman, MS, MCh, \\ Med Hospital, Chennai, Tamil Nadu, India \\ MNAMS, No. 154, Poonamallee High Road, Kilpauk, Chennai, \\ Tamil Nadu, 600010, India (e-mail: v-purush2000@yahoo.com).
}

Indian J Plast Surg:2021;54:29-37.

\begin{abstract}
Keywords

- Contralateral C7

- Superior ulnar collateral artery

- Total Brachial Plexus Palsy

- Vascularized Ulnar Nerve Graft
\end{abstract}

Background Total brachial plexus palsy (TBPP) accounts for nearly $50 \%$ of all brachial plexus injuries. Since achieving a good functional hand was almost impossible, the aim was settled to get a good shoulder and elbow function. It was $\mathrm{Gu}$, who popularized the concept of utilizing contralateral C7 (CC7) with vascularized ulnar nerve graft (VUNG) to get some hand function. We have modified it to suit our patients by conducting it as a single-stage procedure, thereby trying to get a functional upper limb.

Methods From 2009 to 2014, we had 20 TBPP patients. We feel nerve reconstruction is always better than any other salvage procedure, including free muscle transfer. We modified Gu's concept and present our concept of total nerve reconstruction as "ALL IN ONE OR (W)HOLE IN ONE REPAIR."

Results All patients able to move their reconstructed limbs independently or with the help of contralateral limbs. Three patients developed hook grip and one patient was able to incorporate limbs to do bimanual jobs. One important observation is that all the reconstructed limbs regain the bulk, and to a certain extent, the attitude and appearance looks normal, as patients no longer hide it or hang it in a sling.

Conclusion Adult brachial plexus injury itself is a devastating injury affecting young males. By doing this procedure, the affected limb is not dissociated from the rest of the body and rehabilitation can be aimed to get a supportive limb.

\section{Introduction}

Total brachial plexus palsy (TBPP) accounts for nearly $50 \%$ of all adult brachial plexus injuries. ${ }^{1}$ Management of brachial plexus injuries have changed radically in the past couple of decades, but treatment of patients having TBPP is still a major reconstructive challenge and treatment protocol also varies from one center to another. In the majority of patients, only some shoulder and elbow functions were achieved.

However, $\mathrm{Gu}^{2}{ }^{2}$ Doi, ${ }^{3} \mathrm{Tu},{ }^{4}$ Terzis, ${ }^{5}$ and many others, pushed the boundaries and have strived hard to get as much hand functions as possible by combining nerve reconstructions and functioning muscle transfer, which were performed in 2 or 3 stages. Wang ${ }^{6}$ reported direct coaptation of

published online

March 10, 2021
DOI https://doi.org/ 10.1055/s-0040-1719196 ISSN 0970-0358. contralateral C7 (CC7) to the lower trunk and was able to get back hand function after traumatic TBPP. We have modified Gu's concept of utilizing CC7 with vascularized ulnar nerve graft (VUNG) and combining it with other extraplexal donors like spinal accessory, intercostals, C4 motor branches and, occasionally, phrenic nerve and tried to neurotize as many nerves as possible to get overall functional improvement in the whole of the affected upper limb. We call this technique as "ALL IN ONE OR (W)HOLE IN ONE REPAIR."

\section{Materials and Methods}

Twenty patients of TBPP were treated in our institute during 2009 to 2014. This study conforms to the declaration of Helsinki. (c) 2021. Association of Plastic Surgeons of India.

This is an open access article published by Thieme under the terms of the Creative Commons Attribution-NonDerivative-NonCommercial-License, permitting copying and reproduction so long as the original work is given appropriate credit. Contents may not be used for commercial purposes, or adapted, remixed, transformed or built upon. (https://creativecommons.org/licenses/by-nc-nd/4.0/).

Thieme Medical and Scientific Publishers Pvt. Ltd. A-12, 2nd Floor, Sector 2, Noida-201301 UP, India 
Evaluation and operative strategy: Apart from the routine clinical examination, (-Fig. 1) electrophysiological studies

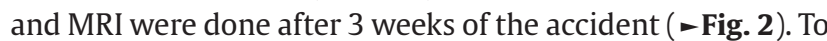
identify early root avulsions, MRI had been found to be very specific. If the roots, especially the C8 and T1, were avulsed, early surgery within a month was planned.

The affected brachial plexus was routinely explored to look for any roots in continuity, and all roots were stimulated to look for any response. Any intact root was utilized for neurotizing the shoulder or elbow muscles. Nerve to serratus anterior was looked for in all cases and a stimulatable nerve indicated an intact proximal root. Doublelevel injury to suprascapular nerve (SSN) was ruled out by tracing it toward the suprascapular notch, and if there was no scarring, we proceeded with the transfer of spinal accessory nerve (SAN) to SSN (1st transfer). The other potential donors like phrenic nerve and C4 motor branches would be identified and kept aside for neurotizing axillary nerve or nerve to biceps and brachialis if required.

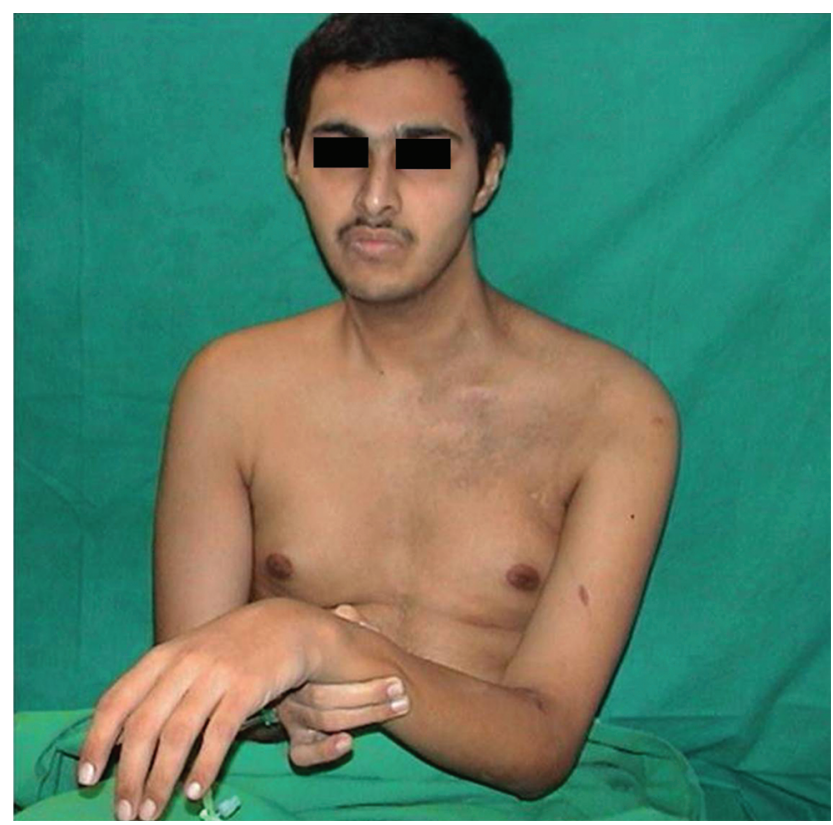

Fig. 1 Global palsy left upper limb.

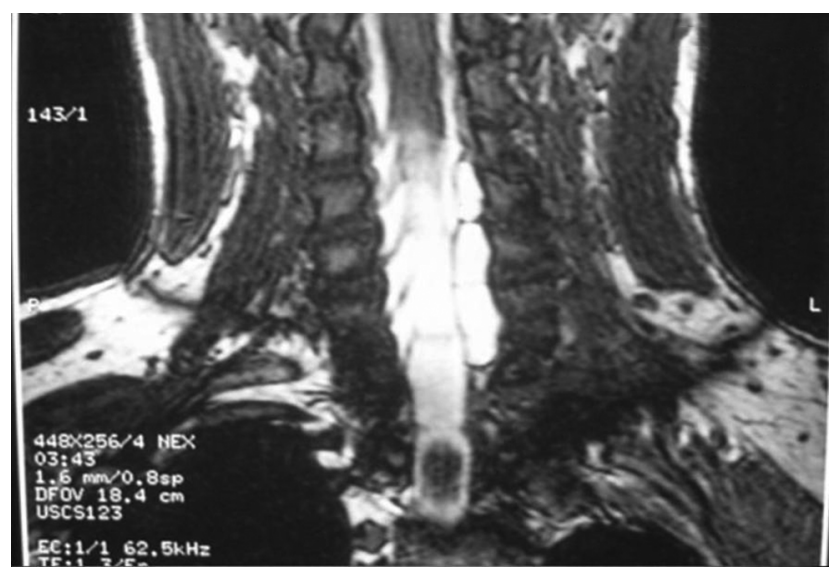

Fig. 2 MRI showing pseudomeningocele on left at all levels and absence of rootlets in the spinal canal.
Next, by a two-team approach, the CC7 and VUNG would be harvested. The whole of CC7 was taken by dividing just proximal to its bifurcation into anterior and posterior divisions. The VUNG was harvested as a pedicled flap, based on the superior ulnar collateral pedicle (-Fig. 3). In our experience, a constant vessel was always found, which nourished nearly $50 \mathrm{~cm}$ of the ulnar nerve. Distally, the ulnar nerve was divided at the wrist level, taking both the main ulnar nerve and the dorsal cutaneous branch. Proximally, the ulnar nerve was divided at its origin from the medial cord. Then VUNG was tunneled subcutaneously through the axilla and across the chest to reach CC7.

The following recipient nerves, namely, axillary (2nd), nerve to biceps (3rd) and brachialis (4th), nerve to triceps (5th), all motor branches of radial (6th) and whole median nerve (7th) were dissected and tagged.

Next, by extending the upper arm incision into the chest wall, three to four intercostal nerves (IC 3, 4, 5, 6) were harvested. At the same time, nerve to pectoralis major (8th) and nerve to serratus anterior (9th) were identified and tagged.

For a better shoulder and elbow function, it was essential to neurotize more muscles around the shoulder and elbow. Once all the dissections were completed, coaptation of nerves were done by both the teams. Our strategy to a total nerve reconstruction is as follows:

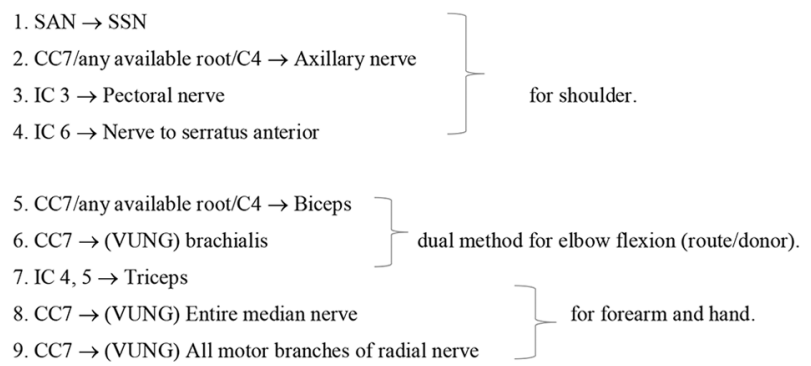

“ALL IN ONE OR (W)HOLE IN ONE REPAIR" refers to this concept of total nerve reconstruction targeting nine major nerves or muscle groups (-Figs. 4 and $\mathbf{5}$ ). The operating time ranged between 5 to 7 hours with a two-team approach. After 3 weeks of immobilization in arm sling, the patients were taught physiotherapy along with electrical stimulation.

\section{Results}

From January 2009 to July 2014, a total of 20 patients with TBPP were operated. Seventeen patients had follow-up of more than 4 years. Of the 17 patients, 16 were males and

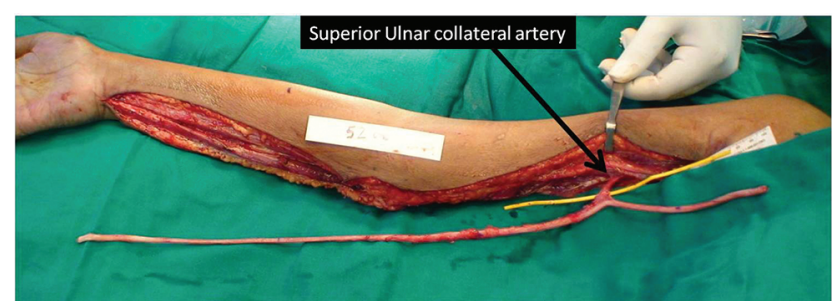

Fig. 3 Pedicled vascularized ulnar nerve graft (VUNG), based on superior ulnar collateral pedicle. 


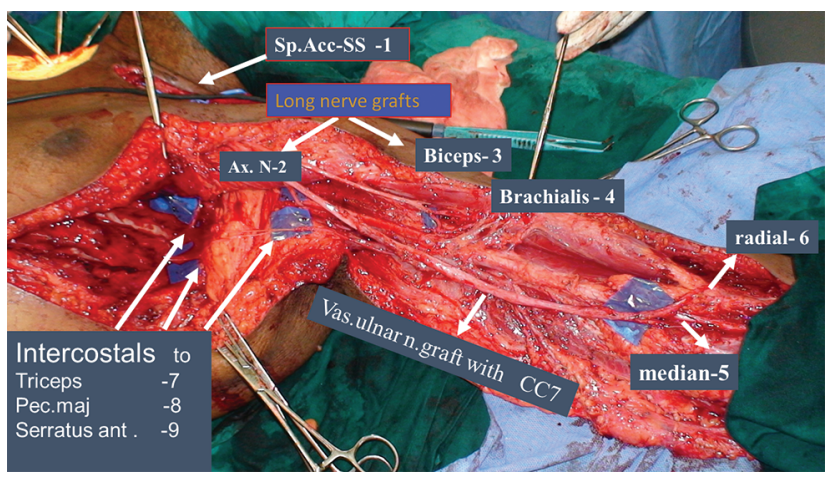

Fig. 4 1. Spinal accessory-suprascapular, 2. axillary, 3.biceps, 4.brachialis-all connected with long nerve grafts (NG) from contralateral C7 (CC7). 5. vascularized ulnar nerve graft (VUNG) to whole median nerve and. 6. VUNG to all motor branches of radial nerve at elbow. 7 . intercostals (ICs) to triceps, 8. pectoralis major, 9. serratus anterior.

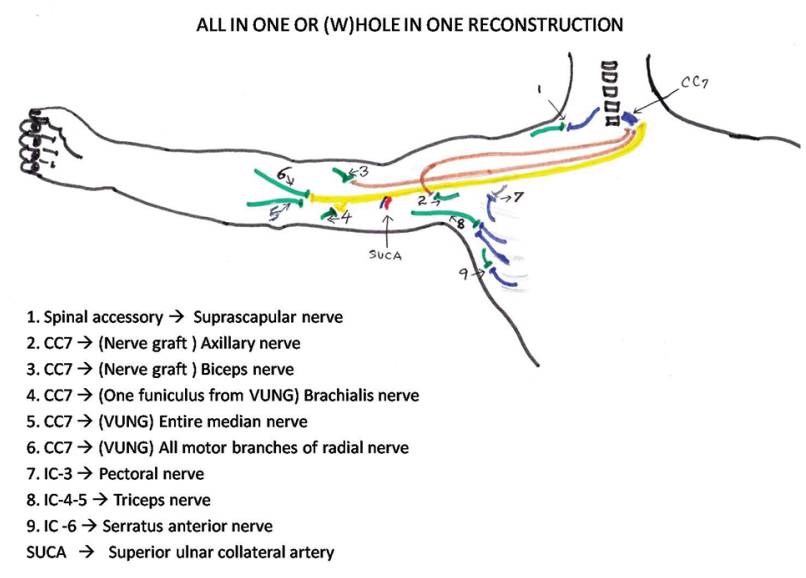

Fig. 5 Diagrammatic representation of All in one or (W) hole in one repair.

Table 1 Donors for axillary nerve

\begin{tabular}{|l|l|l|l|}
\hline S. no & Donor nerve & No of patients & ROM \\
\hline 1. & C4 & 2 & $30^{\circ}$ \\
\hline 2. & Phrenic Nerve & 1 & $40^{\circ}$ \\
\hline 3. & C5 & 5 & $20^{\circ}, 20-30^{\circ}, 80^{\circ}, 15^{\circ}, 45^{\circ}$ \\
\hline 4. & C6 & 1 & $30^{\circ}$ \\
\hline 5. & CC7 & 8 & $50^{\circ}, 60^{\circ}, 40^{\circ}, 80^{\circ}, 10^{\circ}, 50^{\circ}, 100^{\circ}, 40^{\circ}$ \\
\hline
\end{tabular}

Abbreviations: ROM, range of motion.

one female. The mean age of the patients was 26.5 years. All patients had at least three roots avulsed and always had lower root avulsion. Three patients were lost for follow-up. In six patients, $\mathrm{C} 4$ motor branches were utilized for neurotizing either SSN (two patients), axillary (two patients) or nerve to biceps and brachialis (three patients).

\section{Utilization of Ipsilateral Donor Roots}

In one patient, both $\mathrm{C} 5$ and $\mathrm{C} 6$ roots were available. Four patients had C5 alone and one patient had C6 alone. C5 root was used for neurotizing SSN (one patient), axillary nerve (five patients) and nerve to biceps and brachialis (two patients). C6 was used for neurotizing nerve to biceps and brachialis in one patient and axillary and nerve to biceps in another patient.

\section{Shoulder Movements}

Shoulder abduction achieved varied from 45 to $100^{\circ}$, and in all patients, SSN and axillary nerve were neurotized. In two patients, nerve to serratus anterior was also neurotized. In 11 patients, nerve to pectoralis major was neurotized. They also gained shoulder adduction (M2-M3), forward flexion of arm and better stability while swinging the arm.

\section{Axillary Nerve Neurotization}

In 17 cases, long nerve grafts (NG) $(20-25 \mathrm{~cm})$ were used to coapt axillary nerve from various donors ( - Table $\mathbf{1}$ ). The shoulder abduction was found to be better whenever CC7 was used, while ipsilateral roots as donors showed poor results.

\section{Results of Elbow Flexion (- Table 2)}

Satisfactory elbow flexion was achieved in 14 out of 17 patients. Three patients had no elbow flexion and in those three patients, ipsilateral roots were used. CC7 was the best donor (MRC $>\mid=$ M3) compared with SAN, phrenic nerve or ipsilateral roots. Both the nerves, nerve to biceps and nerve to brachialis, were innervated in all cases, whereas dual method of innervation for nerve to biceps and brachialis is our preferred method (NG from any donor for biceps and one funiculus from VUNG for brachialis), as it produced M3-M4 range of movement consistently (-Figs. 6 and 7, -Video 1). Phrenic nerve was usually avoided as a donor nerve as it led to late lung complications due to diaphragmatic paralysis and poor lung function.

\section{Video 1}

Independent elbow flexion of M4 in dual method of neurotization. https://www.thieme-connect.com/products/ejournals/ html/10.1055/s-0040-1719196.

\section{Results of Elbow Extension}

For elbow extension, the nerve to triceps was neurotized. Out of 17 patients, 13 patients had triceps reinnervation. Eleven out of 13 patients developed elbow extension with power ranging from M2-M4. Ten patients had two intercostal nerve (ICN) transfers and had elbow extension 
Table 2 Donors for elbow flexion

\begin{tabular}{|l|l|l|l|}
\hline S. no & Donor nerve & No of patients & MRC \\
\hline 1. & CC7 sequential & 2 & $\mathrm{M} 3, \mathrm{M} 4$ \\
\hline 2. & CC7 using NG & 3 & $\mathrm{M} 3, \mathrm{M} 2, \mathrm{M} 1$ \\
\hline 3. & Phrenic nerve using NG & 1 & $\mathrm{M} 3$ \\
\hline 4. & Spinal accessory nerve using NG & 2 & $\mathrm{M} 3, \mathrm{M} 1$ \\
\hline 5. & Ipsilateral C5 using NG & 1 & $\mathrm{Nil}$ \\
\hline 6. & Ipsilateral C4 using NG & 3 & $\mathrm{M} 4$, nil, M3 \\
\hline 7. & Ipsilateral C6 using NG & 1 & Nil \\
\hline 8. & $\begin{array}{l}\text { CC7-NG for biceps } \\
\text { VUNG one funiculus for brachialis }\end{array}$ & 2 & $\begin{array}{l}\text { M3, M3 } \\
\text { (dual source/route) }\end{array}$ \\
\hline 9. & $\begin{array}{l}\text { C5-brachialis } \\
\text { CC7-biceps (NG) }\end{array}$ & 1 & $\begin{array}{l}\text { M3 } \\
\text { (dual source/route) }\end{array}$ \\
\hline 10. & $\begin{array}{l}\text { C6-biceps } \\
\text { VUNG one funiculus to brachialis }\end{array}$ & 1 & $\begin{array}{l}\text { M4 } \\
\text { (dual source/route) }\end{array}$ \\
\hline
\end{tabular}

Abbreviations: contralateral C7, CC7; MRC, Medical Research Council; NG, nerve graft; VUNG, vascularized ulnar nerve graft.



Fig. 6 Biceps and brachialis innervated by dual method (long nerve graft to biceps and one funiculus from vascularized ulnar nerve graft [VUNG] to brachialis).

M2-M4. Three patients in whom a single ICN transfer was done produced only M1-M3 power. Hence, it was essential to neurotize with, at least, two ICs to achieve good elbow extension

\section{Hand Reanimation using VUNG with CC7}

The VUNG was used to neurotize the median and radial nerve at the level of the elbow. Ten out of 17 patients developed either wrist flexion or extension and finger flexion or extension. One patient had independent control over finger flexion, and he also recovered thenar muscle function. The same patient was using the hand for bimanual functions. Six patients developed wrist flexion of range M1-M3. Four patients had wrist extension of M1 and M3. Six patients recovered finger flexion of M1-M3. Three

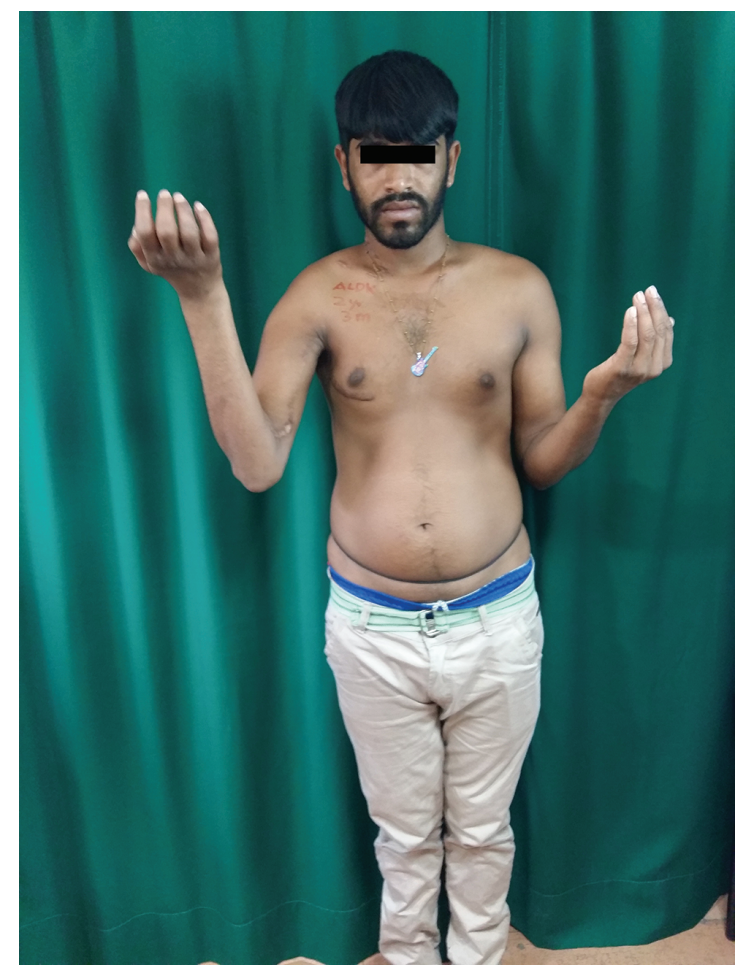

Fig. 7 Good independent elbow flexion in dual method of innervation.

patients developed finger extension. Three patients developed hook grip (-Table 3 ).

\section{Donor Morbidity Following CC7 Harvest}

Eight patients had a donor side morbidity. Six patients had altered sensation or numbness in index and mid finger which recovered spontaneously in 3 to 6 months. One patient had a numbness over the thumb, and this recovered in 1 month duration. One patient had weak triceps which recovered to normal in 4 weeks. 
Table 3 Results of reanimation of hand using VUNG with CC7

\begin{tabular}{|c|c|c|c|c|}
\hline \multirow[t]{2}{*}{ S. No } & \multicolumn{2}{|c|}{ Wrist } & \multicolumn{2}{|c|}{ Finger } \\
\hline & Flexion & Extension & Flexion & Extension \\
\hline 1. & M 2-M3 & M0 & M1-M2 & M0 \\
\hline 2. & M0 & M3 & M0 & M2-M3 \\
\hline 3. & M2-M3 & M0 & M1-M2 & M0 \\
\hline 4. & M3-M4 & M0 & M3(hook grip) & M0 \\
\hline 5. & M3 & M0 & M3 (hook grip) & $\mathrm{M} 2$ \\
\hline 6. & M0 & $\mathrm{M} 2$ & M0 & M0 \\
\hline 7. & M0 & M3 & M0 & $\mathrm{M} 2$ \\
\hline 8. & M2 & M1 & $\mathrm{M} 2$ & M0 \\
\hline 9. & $\mathrm{M} 2$ & M0 & M2-M3 & M0 \\
\hline 10. & M0 & Mo & M2-M3 (hook grip) & M0 \\
\hline
\end{tabular}

Abbreviations: contralateral C7, CC7; VUNG, vascularized ulnar nerve graft.

\section{Case Studies}

Case 1: (-Figs. 8-10); ( - Video 2)

\section{Video 2}

Independent movement of right upper limb doing elbow, wrist and finger extension. https://www.thieme-connect. com/products/ejournals/ html/10.1055/s-0040-1719196.

This 35-year-old male presented with right side TBPP and was operated 8 months after the injury. No ipsilateral roots were available. Seven nerves were targeted.

1. SAN $\rightarrow$ SSN

2. $\mathrm{CC} 7 \rightarrow$ Axillary nerve

3. CC7 $\rightarrow$ Nerve to biceps sequentially connected

4. $\mathrm{CC} 7 \rightarrow$ Nerve to brachialis

5. CC7 $\rightarrow$ (VUNG) anterior interosseous nerve (AIN) hand.

6. CC7 $\rightarrow($ VUNG) posterior interosseous nerve (PIN)

7. ICs $(3,4) \rightarrow$ triceps

At 4 years of follow-up, he had good shoulder and elbow extension. The wrist and finger extensors developed to M3-4 power. He was able to dissociate the movements from the normal limb, and all his right upper limb movements were independent.

Case 2: (-Figs. 11-13); ( - Video 3)

\section{Video 3}

Patient was able to do a good wrist and elbow flexion. Thenar muscles also working showing good thumb palmar abduction. Patient was able to do bimanual jobs. https:// www.thieme-connect.com/products/ejournals/ html/10.1 055/s-0040-1719196.



Fig. 8 Right total palsy.

This 30-year-old male patient presented with left TBPP. He was operated three and a half months after the injury. No ipsilateral roots were available. Spinal accessory, ICs and CC7 were the donors. Nine nerves were targeted.

1. SAN $\rightarrow$ SSN.

2. CC7-NG $\rightarrow$ axillary nerve. 


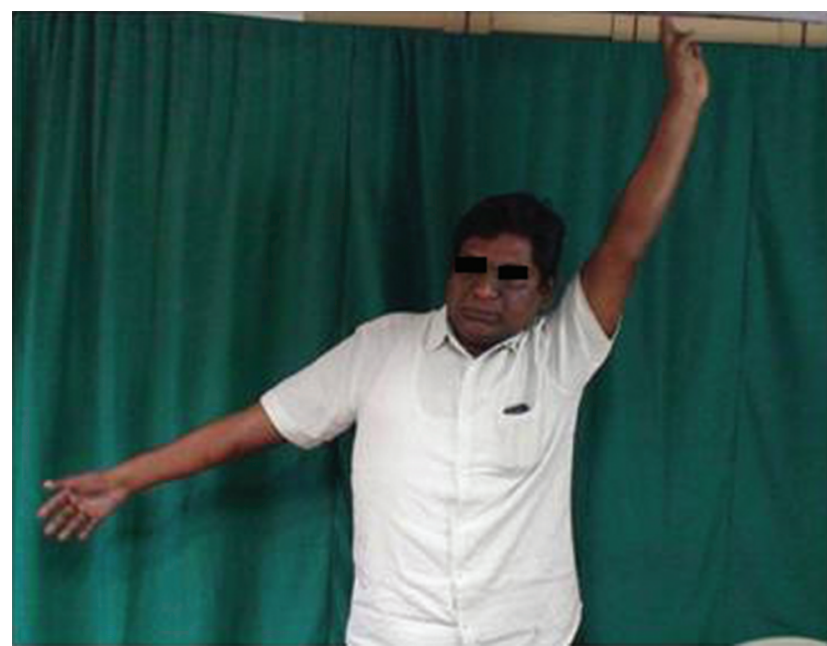

Fig. 94 years follow-up showing good shoulder abduction and elbow extension.

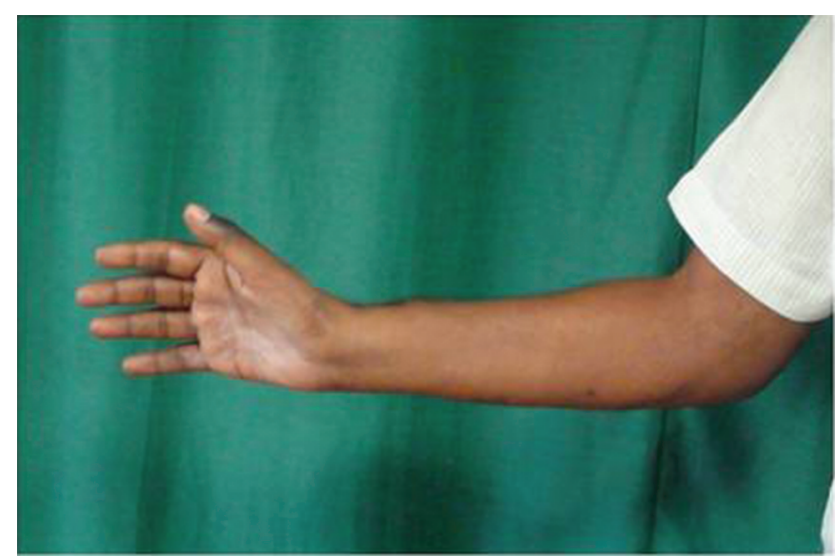

Fig. 10 Extension of wrist and fingers but none of the finger and wrist flexors recovered. Right upper limb movements were independent.

3. CC7-NG $\rightarrow$ nerve to biceps.

4. CC7 $\rightarrow$ nerve to brachialis.

5. ICN (3) $\rightarrow$ nerve to pectoral.

6. ICs $(4,5) \rightarrow$ triceps.

7. IC (3-proximal muscular branch) $\rightarrow$ nerve to serratus anterior

8. $\mathrm{CC} 7 \rightarrow(\mathrm{VUNG})$ entire median nerve.

9. $\mathrm{CC} 7 \rightarrow(\mathrm{VUNG})$ all motor branches of radial nerve.

At 4 years, he had developed a good hook grip and was able to use the hand independently. The thenar muscles also recovered well. It helped him to incorporate the recovered hand in his daily activities. He was able to lift a weight of around $8 \mathrm{~kg}$ with both hands and was doing bimanual jobs.

Case 3: ( - Video 4)

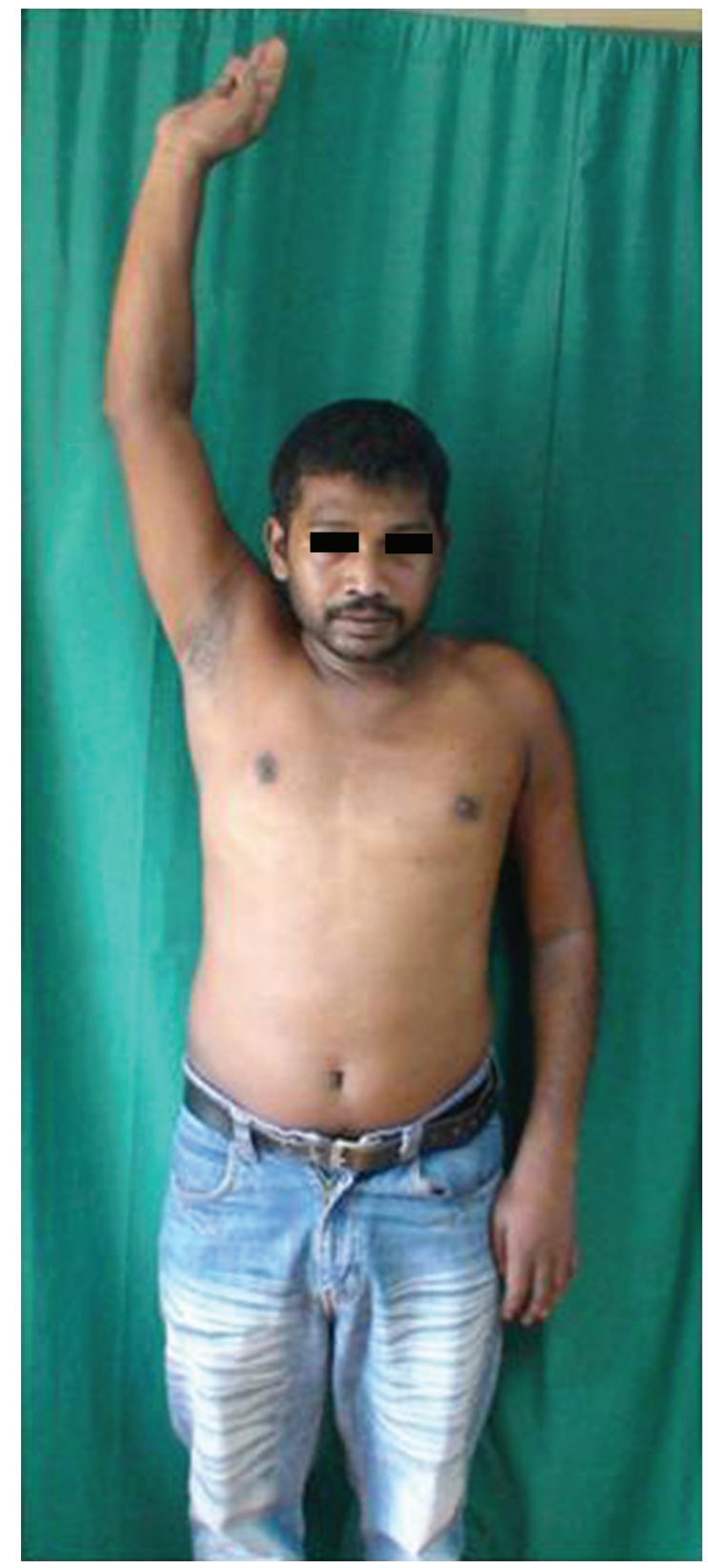

Fig. 11 Left side total palsy.

\section{Video 4}

This patient showing good control of shoulder movements. He can swing his arms while walking. Recovered independent forearm supination and pronation. Now with an outrigger splint, he is increasing the power in the finger flexors. https://www.thieme-connect.com/products/ ejournals/ html/10.1055/s-0040-1719196. 


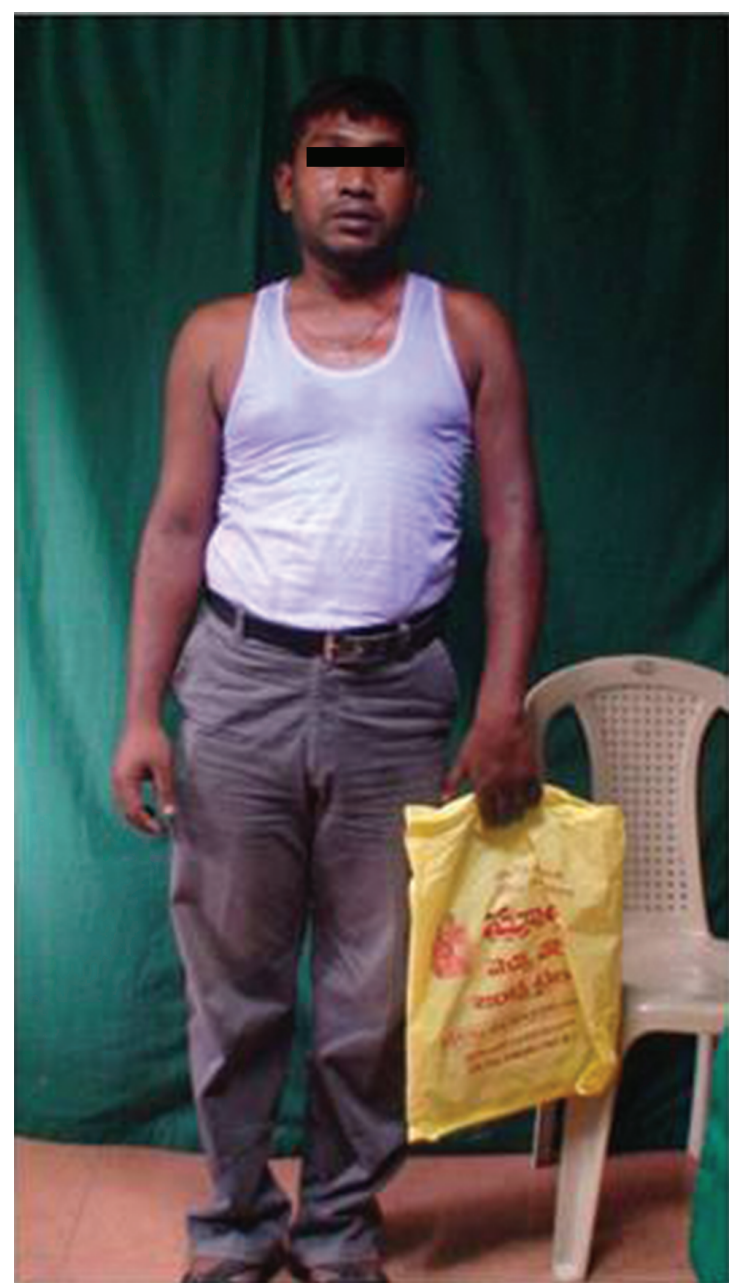

Fig. 124 years postop. Developed hook grip.

A 20-year-old male patient presented with left TBPP, and he was operated 3 months following the injury. No ipsilateral roots were available, and eight nerves were targeted.

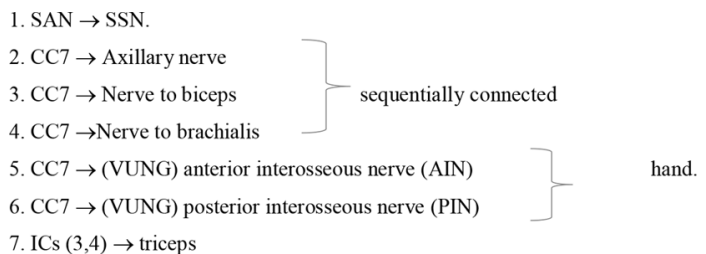

At 4 years of follow-up, he had good shoulder and elbow function. He had wrist and finger flexion of M3. He also developed independent supination and pronation of forearm.

\section{Discussion}

TBPP reconstruction remains a technically challenging surgery. Although the treatment options are many, yet a full functional recovery of hand with a stable shoulder and elbow remains elusive.

Doi was the first person to revolutionize the approach toward global palsy patients. He combined two free

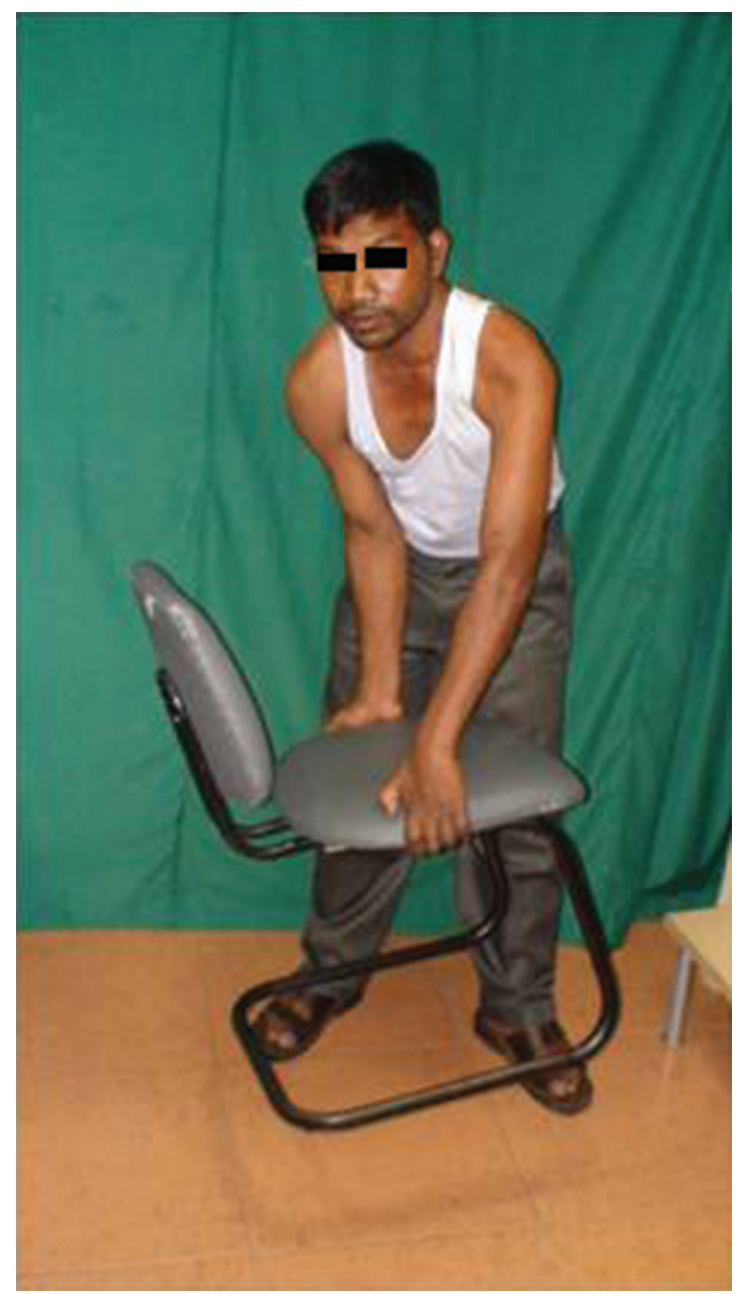

Fig. 134 years postop. Able to do bimanual jobs.

functioning muscle transfers with nerve reconstructions wherever possible and this was done in two stages. Tu further refined it by doing triple free functioning muscle transfers and showed remarkably good results. His idea of doing it in two stages was because of the concern regarding sufficient vascularity to the VUNG. Both of them relied on functional muscle transfer for achieving prehensile hand functions.

Our technique based on using $\mathrm{CC} 7$ for reconstruction was similar to Gu's technique. Gu suggested a radically different idea of utilizing CC7 as a major donor nerve and combined it with VUNG as a conduit. This procedure encouraged large quantum of $\mathrm{CC} 7$ neurons to grow through a VUNG and reached faster to affected side muscle units; hence, achieving neuronal recovery, especially of the hand functions. Gu used CC7 to neurotize the musculocutaneous nerve for elbow function and median nerve for hand function. In our study, initially, one funiculus from the VUNG close to the respective recipient nerves was taken, and they were sequentially connected to all the recipient nerves, namely, axillary, nerve to biceps and brachialis and all motor branches of radial and median nerve. These patients were achieving good shoulder and elbow function but poor or no hand functions (-Figs. 14, 15, 16) This might be attributed to the "neuronal steal" by the proximal coaptations. Hence, in the later 
reconstructions, long NG from CC7 or other donors were used for neurotizing the shoulder and elbow, while the entire VUNG was used exclusively for both radial and median nerves. For elbow flexion when CC7 was used with long NG to neurotize both nerve to biceps and brachialis, the elbow flexion achieved was inconsistent. For this reason, we started doing dual method of neurotization for elbow flexion, that is, using CC7/ipsilateral available roots with long nerve graft to neurotize nerve to biceps and using one funiculus from VUNG to neurotize nerve to brachialis. In all these patients, elbow flexion of M3-M4 was consistently achieved.

Initially, Gu was innervating both median and radial nerves, and he subsequently felt that both these antagonistic nerves should not be innervated by the same donor nerve based on his results. ${ }^{2}$ He neurotizes only musculocutaneous and median nerve or median nerve only. Unlike $\mathrm{Gu}$, we always innervated both median and all motor branches of radial nerve in all our patients to get more functions of the forearm muscles. In spite of antagonistic innervation, in two patients, there was recovery of muscles innervated by both the median and radial nerve (-Video 5). In the remaining patients, the recovery was either of median or radial nerve.

\section{Video 5}

In this patient, although not independent, both finger flexors and extensors are recovering. https://www.thieme-connect. com/products/ejournals/ html/10.1055/s-0040-1719196.

Wang $^{6}$ had a different approach. His idea was to do direct coaptation of CC7 to the lower trunk by extensively mobilizing the same and passing it through the pre spinal route, with or without humerus shortening. For elbow flexion, he diverted the medial cutaneous nerve of arm to musculocutaneous nerve. In his initial report, he did not address the extensors of wrist and fingers. But subsequently he added phrenic nerve to the cut end of the posterior division of lower trunk (which was necessary for extensive mobilization of lower trunk). This helped in getting some extensor function in his cases. ${ }^{7}$ Moreover, he used entire CC7 only to lower trunk concentrating on the hand function. But we used as many donor nerves as possible to try reanimate shoulder, elbow and hand functions.

One important observation was that all reconstructed limbs regained the bulk, and to a certain extent, the attitude and appearance were normal. These patients no longer hid it or hung it in a sling, whereas they were able to swing their arm normally while walking. Moreover, they were not wasting the function of normal limb in holding the affected limb and thereby becoming handicapped for not using both upper limbs. When we neurotized as many muscles as possible, the reconstructed limb also did not look like a paralyzed limb, and it could function as a good supportive limb.

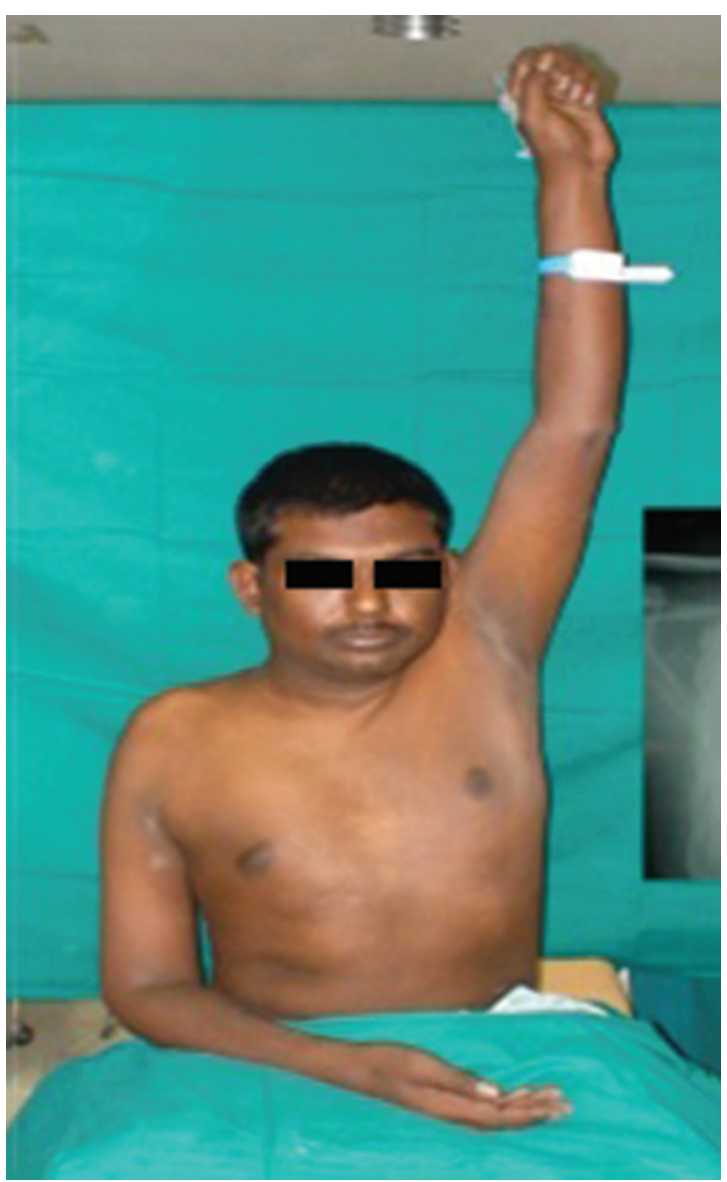

Fig. 14 35-year-old male with total palsy right side, 3 months.

\section{6 nerves targeted}

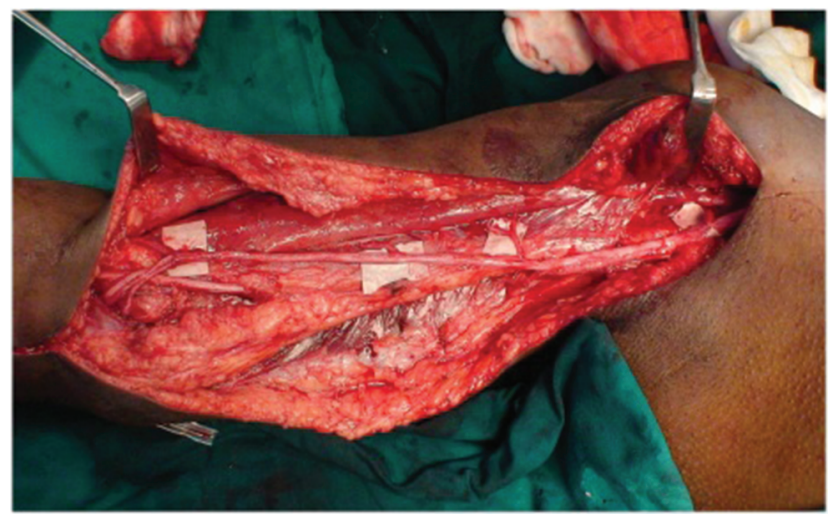

Fig. 15 Six nerves targeted. Both biceps and brachialis reinnervated (one funiculus each from vascularized ulnar nerve graft [VUNG]). 


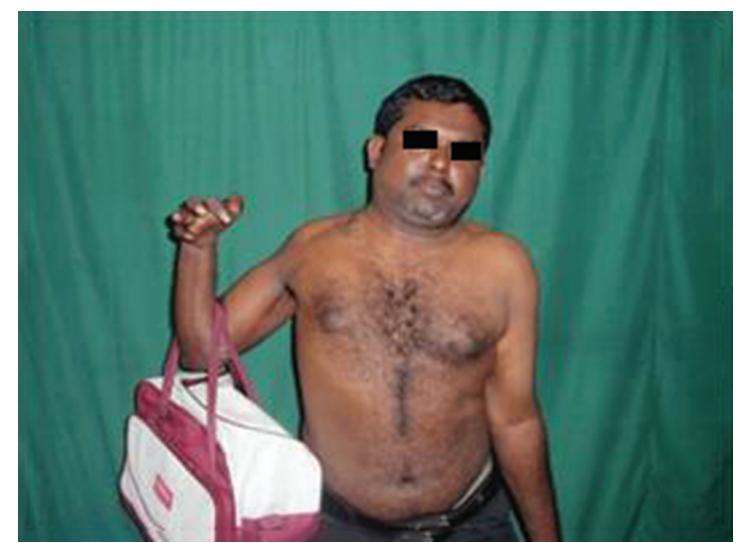

Fig. 16 Demonstrating good elbow flexion.

\section{Conclusion}

ALL IN ONE or (W) HOLE IN ONE reconstruction aims at neurotizing maximum number of important muscles, using as many donor nerves as possible in a single-stage procedure. Neurotization of additional muscles like pectoralis major and serratus anterior significantly improves stability and functionality of the shoulder joint. Dual innervation for elbow flexion provides foolproof technique of achieving a good elbow flexion. Good recovery of hand and wrist function is possible using CC7 with pedicled VUNG in few patients, and these patients are able to use it as a good supportive hand.

\section{Conflicts of Interest}

None declared.

\section{References}

1 Jain DK, Bhardwaj P, Venkataramani H, Sabapathy SR. An epidemiological study of traumatic brachial plexus injury patients treated at an Indian centre. Indian J Plast Surg 2012;45(3):498-503

2 Zhang CG, Gu YD. Contralateral C7 nerve transfer - Our experiences over past 25 years. J Brachial Plex Peripher Nerve Inj 2011;6(1):10

3 Doi K, Hattori Y, Ikeda K, Dhawan V. Significance of shoulder function in the reconstruction of prehension with double free-muscle transfer after complete paralysis of the brachial plexus. Plast Reconstr Surg 2003;112(6):1596-1603

4 Yuan-KunTu, Chung KC. Surgical procedures for recovery of hand function In Practical Management of Paediatric and Adult Brachial Plexus Palsies. 1st ed. USA: Elsevier; 2011: 271-300

5 Terzis JK, Kostopoulos VK. Vascularized ulnar nerve graft: 151 reconstructions for posttraumatic brachial plexus palsy. Plast Reconstr Surg 2009;123(4):1276-1291

6 Wang SF, Li PC, Xue YH, Yiu HW, Li YC, Wang HH. Contralateral C7 nerve transfer with direct coaptation to restore lower trunk function after traumatic brachial plexus avulsion. J Bone Joint Surg Am 2013;95(9):821-827, S1-S2

7 Wang SF, Li PC, Xue YH, Zou JY, Li WJ, Li Y. Direct coaptation of the phrenic nerve with the posterior division of the lower trunk to restore finger and elbow extension function in patients with total brachial plexus injuries. Neurosurgery 2016;78(2):208-215 